\title{
Influence of linear versus network corridors on the movement and dispersal of the bush-cricket Metrioptera roeseli (Orthoptera: Tettigoniidae) in an experimental landscape
}

\author{
ANDERs ERIKSSON, MatTHEw LOW and Åsa BERGGREN* \\ Department of Ecology, PO Box 7044, Swedish University of Agricultural Sciences, SE-75007 Uppsala, Sweden; \\ e-mails: asa.berggren@slu.se; anders.eriksson@speedmail.se; matt.low@slu.se
}

Key words. Tettigoniidae, Metrioptera roeselii, movement, corridor, nodes, intersections, cross-roads, linear elements

\begin{abstract}
Linear landscape elements are generally considered beneficial for promoting the movements of species between isolated habitats. However, relatively little consideration has been given to the effect of interconnections (nodes) between these elements: e.g. a simple linear element offers limited options for movement, whereas a network of such structures provides an exponential increase in potential pathways. In this pilot study we compared two experimental landscapes (single versus a lattice of four interconnected linear elements) in terms of their effect on the movement of males of Roesel's bush-cricket (Metrioptera roeseli) (Orthoptera: Tettigoniidae). Emigration of released bush-crickets from experimental landscapes was greater if there was a single rather than a lattice of linear elements (corridors). In the landscape with a lattice of corridors, $50 \%$ of the bush-crickets changed their direction of movement at nodes at least once. There was also evidence that nodes were attractive to bush-crickets; a higher proportion of individuals were found in and around nodes than in adjoining corridors, with the strength of this effect (i.e. aggregation at nodes) increasing with time. Thus nodes may not only affect the direction of movement but may also act as a local attractant. These effects may have an important role in the movement of species and their success in colonizing fragmented landscapes. These results indicate that in future landscape planning more consideration should be given to the connectivity between linear landscape elements as it is likely to be important in determining the movement and distribution of species.
\end{abstract}

\section{INTRODUCTION}

Many species use linear elements of habitat (or "corridors") for moving between habitats: e.g. butterflies (Söderström \& Hedblom, 2007), beetles (Jordan et al., 2007), crickets (Berggren et al., 2002, Brouwers et al., 2011), reptiles (Delgado Garcia et al., 2007), amphibians (Brown et al., 2006), birds (Gillies \& Clair, 2008) and mammals (Pardini et al., 2004). Although the correlation between connectivity and corridors is not always clear (e.g. Davies \& Pullin, 2007), linear landscape elements are generally acknowledged as having a positive effect on population persistence, which results from an increased connectivity of fragmented populations (Tischendorf et al., 2000; Brudvig et al., 2009). The value of linear landscape elements is usually discussed in terms of their quality or size (Lees \& Peres, 2008; Cooke \& Zack, 2009), with little attention focused on their spatial arrangement - i.e. how the corridors are oriented in relation to each other and the additional movement opportunities that this may create (but see Wood \& Samways, 1991). Linear landscape elements may not function in isolation, but instead intersect and form a network that provides linkage to other linear elements / habitats (these intersections are commonly known as "nodes"; Forman et al., 1981). For an individual utilizing a linear element, a single corridor gives an individual only two movement options if it remains within the corridor (forward and back); however, the presence of nodes gives an individual additional options to access other areas of habitat (e.g. left and right). The frequency of nodes in landscapes varies greatly (Berggren et al., 2001), potentially resulting in different opportunities for the individuals inhabiting these landscapes to utilize and spread through these areas.

How spatial arrangement of corridors affects populations and the movement of individuals is largely unexplored. It is possible that nodes, in addition to providing access to alternative routes and habitats in the landscape, also create local areas of higher density of the focal species resulting from immigration into the node from many directions (de Jong \& Kindvall, 1991; Å. Berggren, pers. obs.). Local high density effects at nodes could be important in understanding the ecology of species utilizing these areas as a primary habitat (e.g. mating success, genetic diversity and viability of populations; Berggren, 2009; Gascoigne, 2009). This suggests that an increased knowledge of how the spatial arrangement of linear elements affects the spatial distribution of different species would be a valuable addition to the understanding of landscape ecology, species management and the prediction of how species move through the landscape. The testing of such ideas can be easily undertaken on nonflying insect species whose movements are restricted to habitats that can easily be fragmented in an experimental framework. One such species is the Roesel's bush-cricket (Metrioptera roeseli; Hagenbach 1822), a species that

\footnotetext{
* Corresponding author.
} 
commonly uses linear grass verges and ditches as primary habitat and corridors in agricultural landscapes (Berggren et al., 2002).

Linear elements and nodes are known to affect population parameters of Roesel's bush-cricket (Berggren et al., 2001); population growth is faster in landscapes with more linear elements and positively correlated to the number of nodes (i.e. connections between linear elements). It is thought that this population response to node-rich habitat in the currently expanding distribution of this species in Sweden, results from an average increase in individual reproductive success and an increased likelihood of dispersing individuals finding suitable habitat. Thus, to gain a better understanding of how nodes influence the spatial distribution of male Roesel's bush crickets in agricultural environments, we examined individual movement within two experimental landscapes differing in the spatial arrangement of the same area of linear habitat. One spatial arrangement consisted of a single linear element (hereafter "Single landscape"; Fig. 1) and another a network of corridors (four linear elements connected via four nodes, hereafter called "Lattice landscape"; Fig. 1). Our aim was to examine the potential role of nodes in influencing the movement of male $M$. roeseli within these linear elements, rather than between larger habitat patches, because these linear elements constitute a large proportion of the total habitat area utilized by $M$. roeseli within the agricultural landscapes of central Sweden, where this species is currently increasing in abundance (Berggren et al., 2001). We expected that when presented with a node-rich landscape, individuals would: (1) utilize the nodes to change their general direction of movement (de Jong \& Kindvall, 1991), (2) after an initial period of exploration, be more likely to be located in and around nodes than within the linear habitat elements linking nodes (Kindvall et al., 1998), and (3) have lower rates of emigration from a node-rich landscape than a Single landscape. We used the Single landscape as a control for interpreting any distribution patterns found within the Lattice landscape for example, if bush-crickets aggregated at the first node they encountered, was this because of some intrinsic quality of the node or a function of a simple stopping rule based on distance.

\section{MATERIAL AND METHODS}

\section{The species}

Roesel's bush-cricket is common in southern and central Europe, as well as in Finland and Latvia (Marshall \& Haes, 1988). In Sweden it is mainly found around Lake Mälaren but it is currently undergoing a range expansion (Pettersson, 1996; Preuss et al., 2011). The species over-winters as eggs, which are laid in grass stems during summer and autumn and hatch in May 1 or 2 years later (Ingrisch, 1986). The nymphs progress through six instars before becoming adults (Marshall \& Haes, 1988). In Sweden adults are active until October when they are killed by frost. Roesel's bush-cricket is 13-26 $\mathrm{mm}$ in length, shortwinged and moves by walking or jumping (Marshall \& Haes, 1988). The species-preferred habitat is moist un-grazed tall grass areas. These bush-crickets usually avoid open spaces without tall grass cover (Berggren, 2004), and often use road

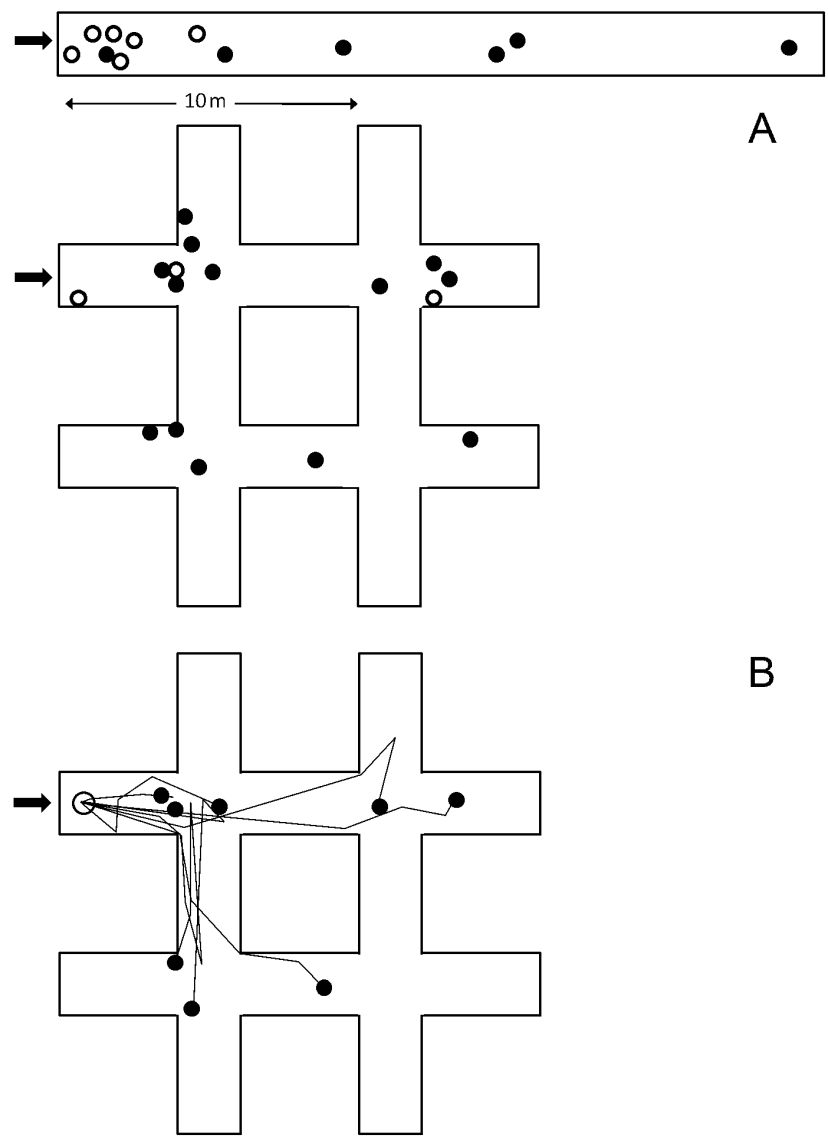

Fig. 1. Spatial arrangement of the corridors in the Single landscape consisting of two $56 \mathrm{~m}$ long $2 \mathrm{~m}$ wide corridors (total area $=112 \mathrm{~m}^{2}$; only the first $26 \mathrm{~m}$ are represented), and Lattice landscape consisting of four $16 \mathrm{~m}$ long $2 \mathrm{~m}$ wide corridors arranged so that there are four intersections (nodes) (total area $=112 \mathrm{~m}^{2}$ ). Both areas consisted of preferred habitat for bush-crickets (high grass) surrounded by areas of mown grass. Circles show the final recorded position of bush-crickets: A - open circles are the final positions of bush-crickets that were only found during the first census after release, and closed circles are the final positions of those that were recorded in 2-8 subsequent censuses. B - closed circles show the final positions of 8 individuals that were recaptured on the third day, the open circle the release point and the lines their individual patterns of movement. Individuals were released at the ends of all the corridors during the course of the experiment; however, to make the interpretation easier the final positions are shown relative to a standardized release point in the figure (arrows).

verges, ditches and similar linear landscape elements for dispersal (Berggren et al., 2001). The males stridulate continuously on warm summer days and their unique mating call makes them easy to survey (Marshall \& Haes, 1988). Stridulation in Orthoptera is primarily for attracting females that move between the males' calling sites. The song's characteristics are an important factor in the mate choice for many Orthoptera (Gwynne, 2002). Males can increase the number of females they attract by adjusting their stridulation position and the optimal position for a male will depend on factors such as the density of vegetation and other males (Gwynne, 2002). The movement of males during the breeding season is therefore partly driven by the need to find a good calling position that takes into account local habitat characteristics and location of conspecifics. 


\section{Study individuals}

We used hand-nets to collect male nymphs of $M$. roeseli from a population in southeastern Sweden $\left(59^{\circ} 35^{\prime} 8.15^{\prime \prime} \mathrm{N}\right.$, $\left.16^{\circ} 28^{\prime} 38.81^{\prime \prime} \mathrm{E}\right)$. The males were housed in cages with ad libitum access to food and water until they reached maturity (3-4 weeks). The cages were kept at room temperature $\left(18-20^{\circ} \mathrm{C}\right)$ and under normal daylight conditions. All individuals were checked before release to ensure they were healthy and could stridulate.

\section{The experimental area}

The experimental study was conducted from July 31 to August 23 in 2007 during the bush-cricket's breeding season in an agricultural landscape outside $M$. roeseli's current distribution $\left(59^{\circ} 50^{\prime} 22.64^{\prime \prime} \mathrm{N}, 17^{\circ} 47^{\prime} 46.41^{\prime \prime} \mathrm{E}\right)$. This had the advantage that all the bush-crickets found during the censuses were released individuals. The vegetation in the experimental area consisted of preferred habitat of the species; un-grazed high grass and clover, predominantly Trifolium pratense and Phleum pratense. In the study area we created two different configurations of linear elements with the same area of $112 \mathrm{~m}^{2}$. In the "Single landscape" there was a straight linear element, $56 \mathrm{~m}$ long and $2 \mathrm{~m}$ wide (Fig. 1) and in the "Lattice landscape" four interconnected linear elements ( $16 \mathrm{~m}$ long and $2 \mathrm{~m}$ wide) with four nodes (Fig. 1). The widths of the corridors were similar to the linear elements in agricultural land that are their primary habitat and utilized by the species for movement (Berggren et al., 2002). The grass in a $2 \mathrm{~m}$-wide zone around the experimental area was mown to a height of $1-4 \mathrm{~cm}$ and kept at this height throughout the experiment. Two experimental areas of each corridor type were created so experiments could be run in parallel and the grass in the area between the sites was not mown.

\section{Release of individuals and censuses}

A total of 47 individuals were released, with only one individual at a time released in each experimental area. To identify the $M$. roeseli, bee-tags (J. Svenssons Vaxfabrik, Sweden) of different colours and with different numbers were glued to their pronotum. The release point was $0.5 \mathrm{~m}$ from the end of a corridor and $1 \mathrm{~m}$ from each side. In the Single landscape there were two possible starting points: one at each end. In the Lattice landscape, there were 8 possible starting points: one at each end of the four corridors. The release point for each individual was chosen at random to minimize the confounding effects of direction or microhabitat. The crickets were only released on warm $\left(>18^{\circ} \mathrm{C}\right)$ days to ensure they were not inhibited in their movements by cold, and increase census success so that the results of the releases can be compared. They were released at 08:00, two hours before the first census. Censuses were undertaken at 10:00, 13:00 and 16:00, when the bush-crickets were located by listening for stridulating males and their positions mapped after using their individual tag to confirm their identity. This involved carefully positioning oneself to observe the cricket and using a measuring tape to determine its position relative to the side and end of the corridor $( \pm 0.1 \mathrm{~m})$. The censuses appeared to have no effect on their behaviour as they resumed stridulating within $10 \mathrm{~min}$. All crickets were re-captured after seven or eight censuses post-release, or earlier if the weather became cold and wet (minimum of 5 census periods). They were all re-captured before the next cohort ( 1 bush-cricket per area) was released in order to prevent male-male interactions influencing their movement and settlement behaviour. Data collected in this and other studies (Berggren et al., 2002; Berggren, 2005) show that this time-frame is more than adequate to allow males to move to any location within the experimental corridors. Distance that an

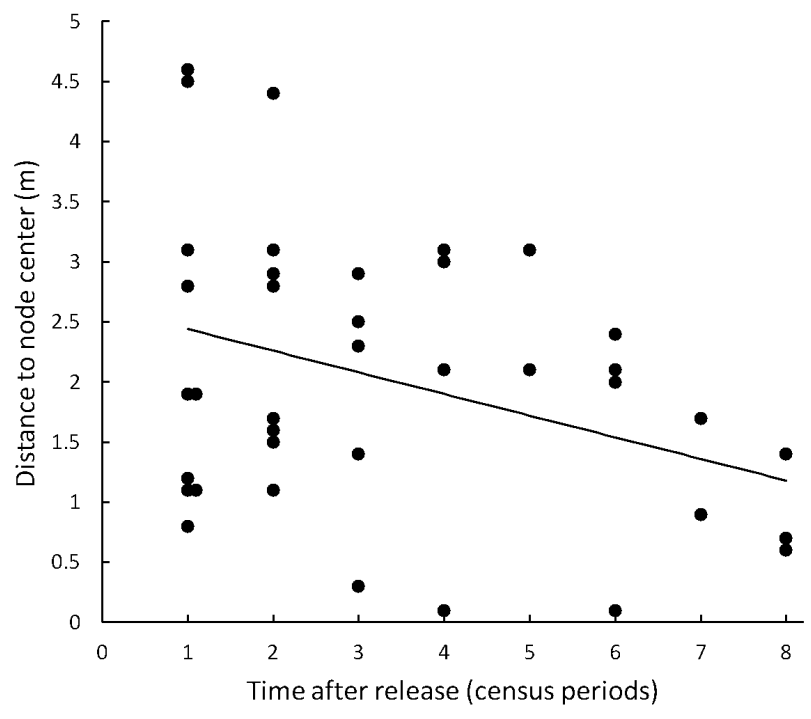

Fig. 2. The relationship between the distance of individuals from nodes and time since their release in the Lattice landscape. Points show all positions recorded post-release and the line shows the GLMM prediction (see results).

individual was from the nearest node in the Lattice landscape was based on an individual's location relative to the central point of the nearest node at the time of each census. Speed of movement was calculated from the Euclidian distance between successive census positions and time since release.

\section{Analyses}

To assess whether the crickets that were released within the Lattice landscape were more likely to be found near a node as the experiment progressed, we used a general linear mixed model (GLMM in MLwiN 2.20; Rasbash et al., 2009) with time-since-release as a fixed effect, and individual identity as a random effect, to account for repeated measures. To examine the importance of time-since-release on predicting distance to the nearest node, we used a likelihood ratio test to compare the model that included this term, to one that did not. We visually assessed whether any time-dependent aggregations at the nodes in the Lattice landscape were a simple function of the bushcrickets stopping a few meters from their release site (and hence ending up within the first node) by comparing the last-known positions in the Single and Lattice landscapes; if bush-crickets stopped at nodes in the Lattice but showed no tendency to stop at similar distances within the Single landscape, this would lend support to the idea that the nodes themselves were influencing bush-cricket movement.

To compare the Lattice and Single landscapes in terms of probability of detection during a census (i.e. stridulating or not) and the probability of individuals leaving an experimental area between censuses, we used Cormack-Jolly-Seber live-recapture models in the program MARK (White \& Burnham, 1999). Encounter histories for each individual $(n=47)$ were derived from their subsequent observation within the experimental landscape during each of the eight census periods. We created a set of candidate models based on four variants of the survival (emigration) parameter $(\Phi$; whether differences existed between landscape types; if differences existed between censuses) and two variants of the detection parameter ( $p$; detection constant for all censuses but potentially varying between the two experimental landscapes). Models were compared using $\mathrm{AIC}_{\mathrm{c}}$ and parameter estimates and their associated standard errors calcu- 
lated from the model set using AIC-weighted model averaging (Burnham \& Anderson, 2002). Means \pm SE are given.

\section{RESULTS}

A total of 47 individuals were released (28 in Single landscape and 19 in Lattice landscape); however, after release only 28 individuals were subsequently recorded in the experimental landscapes during post-release censuses (12 in Single, 16 in Lattice).

\section{Influence of nodes on position of bush-crickets within experimental landscapes}

Bush-crickets in the Lattice landscape changed their direction of movement roughly proportional to available dispersal directions, with eight individuals (50\%) utilizing the nodes to change direction in the experimental corridors at least once (see Fig. 1a, b - note that the final position of two individuals was the corridor in which they started Fig. 1a). As the experiment progressed, individuals in the Lattice were more likely to be found near a node (Fig. 2). The GLMM that included the time-sincerelease term [Distance to node $(\mathrm{m})=2.62 \pm 0.31-0.18 \pm$ $0.07 *$ census periods since release] was a significant improvement over the model without this term (likelihood ratio test; $\chi^{2}=5.6, P=0.018$ ). Comparisons of the lastknown positions in the Single and Lattice landscapes of the 28 individuals that were followed during post-release censuses show that the time-dependent aggregations at the nodes in the Lattice landscape were not a simple function of the bush-crickets stopping a few meters from their release site (and hence ending up within the first node). In the Single landscape, bush-crickets showed no tendency to aggregate at that distance (Fig. 1), suggesting that the aggregations at Lattice nodes were some function of the nodes themselves or the spatial arrangement of the corridors.

\section{Influence of nodes on rates of emigration of bush-crickets from experimental landscapes}

The probability of detecting a bush-cricket, if one was present during a census, did not differ between Lattice and Single experimental landscapes (model-averaged estimates of the detection parameter $(p)$ in Table 1: $0.46 \pm$ 0.06 versus $0.47 \pm 0.07$ probability of an individual stridulating and therefore being detected during a census); however there was a large difference between the two landscapes in the probability of an individual remaining within a corridor (i.e. apparent survival / emigration) between each census (model-averaged estimates of the "survival" parameter $(\Phi)$ in Table 1: Lattice $=0.89 \pm$ 0.07 ; Single $=0.64 \pm 0.09$ probability of an individual surviving and remaining within the experimental arena). This difference in emigration probability was also apparent in the average number of observations per individual after release (Lattice versus Single; $4.5 \pm 0.8$ versus $2.7 \pm 0.7$ census periods post-release), and the finding of five individuals in the surrounding area of the Single landscape as compared to none in the Lattice landscape. A comparison of survey times to known locations for all individuals (total positions $=57$; averaged per indi-
TABLE $1 . \mathrm{AIC}_{\mathrm{c}}$-ranked candidate model set showing the relative importance of experimental landscape structure (landscape) and time since release (census) on apparent survival/ emigration $(\Phi)$ and detection probability $(p)$ during censuses of bush-crickets in the Lattice and Single experimental landscapes $\left(.=\right.$ parameter held constant). $\mathrm{AIC}_{\mathrm{c}}$-weights $\left(w_{i}\right)$ show the relative strength of support for each model and were used to generate the model-averaged parameter estimates; $k$ is the number of estimated parameters in the model.

\begin{tabular}{lcccc}
\hline Model description & $k$ & $\mathrm{AIC}_{\mathrm{c}}$ & $\Delta \mathrm{AIC}_{\mathrm{c}}$ & $w_{i}$ \\
\hline$\Phi_{\text {landscape }} \mathrm{p}$. & 3 & 270.4 & 0 & 0.72 \\
$\Phi_{\text {landscape }} \mathrm{p}_{\text {landscape }}$ & 4 & 272.5 & 2.1 & 0.25 \\
$\Phi . \mathrm{p}$. & 2 & 277.3 & 6.9 & 0.02 \\
$\Phi_{.} \mathrm{p}_{\text {landscape }}$ & 3 & 278.8 & 8.4 & 0.01 \\
$\Phi_{\text {census }} \mathrm{p}$. & 9 & 289.9 & 19.5 & 0 \\
$\Phi_{\text {census }} \mathrm{p}_{\text {landscape }}$ & 10 & 291.1 & 20.7 & 0 \\
$\Phi_{\text {landscape, census }} \mathrm{p}$. & 17 & 293.9 & 23.5 & 0 \\
$\Phi_{\text {landscape, census }} \mathrm{p}_{\text {landscape }}$ & 18 & 296.6 & 26.2 & 0 \\
\hline
\end{tabular}

vidual) showed no clear evidence of a difference between the two landscapes in terms of individual average speeds of movement (Single versus Lattice; $0.79 \pm 0.23$ versus $\left.1.07 \pm 0.26 \mathrm{~m} \mathrm{hr}^{-1} ; t=0.79, \mathrm{df}=26, P=0.44\right)$.

\section{DISCUSSION}

The higher apparent survival (i.e. survived and did not emigrate) of individuals within the Lattice compared with the Single landscape suggests that the probability of an individual emigrating from the experimental area was a function of the spatial arrangement of the corridors. Potentially the Lattice landscape was better in terms of satisfying the needs of bush-crickets (e.g. shelter from predation or more-attractive stridulation sites), which decreased an individuals' risk of predation or tendency to look for somewhere better. Thus, the results can be viewed in terms of habitat selection, with nodes being viewed as a more highly valued habitat patch linked by less-preferred linear elements. Lower emigration rates from the Lattice may also be a function of the fact that it contains parallel and perpendicular pathways that "catch" individuals that exit from the side of a linear element (an example of the "drift-fence effect"; Dramstad et al., 1996): something that would be much less likely to happen if an individual exited a corridor in a Single landscape.

With half of the bush crickets in the Lattice landscape using nodes to change their general direction of movement at least once suggests they were either: (1) zigzagging within the corridors (e.g. a form of random walk; Fig. 1b) and, thus, at nodes they randomly changed their general direction at a rate proportional to the frequency and amplitude of their zigzag movements, or (2) could recognize that additional movement options existed at nodes and in some cases changed their direction of movement at these points. Regardless of the mechanism, if we extrapolate this change in direction of movement at nodes to a broader scale, the emerging species distribution patterns will differ between landscapes with different spatial 
arrangements of the corridors. In landscapes with many nodes, dispersal paths of those individuals remaining within habitat corridors will tend to reflect the greater movement options, while the paths followed by individuals in landscapes with few nodes will be straighter and simpler (Proulx et al., 2005). Species in node-rich landscapes potentially have a greater ability to tolerate the negative effects of habitat barriers that hinder movement along some corridors (McRae et al., 2008) while in nodepoor landscapes single barriers could have a larger effect on population distribution, at least in the short term. Thus, when comparing species that are extending their distributions in different landscapes, it should be kept in mind that the speed of spread is likely to be correlated with the spatial arrangement of the corridors and location of barriers to dispersal. Also, when using corridors to connect important habitats, one possibility is that corridor networks (like the Lattice) will be more effective in limiting the loss of individuals that might otherwise leave the corridor (via the "catching" effect postulated above).

The nodes also appeared to be attractive to individuals, a pattern which became stronger as the experiment progressed (Figs 1 and 2). Thus, individuals need not recognize the value of a node as a dispersal enhancer for it to be ecologically valuable. The area of suitable habitat surrounding an individual positioned in a node is greater than for an individual positioned in a corridor; for male bush-crickets, this means that nodes offer a greater area for attracting females by stridulating. If so, one prediction is that nodes may also be attractive for females, as encounters with mates would increase and the male-male competition in these areas would ensure that average quality of the males at nodes was higher than in corridors (Kindvall et al., 1998; Gascoigne et al., 2009). If these findings are transferrable to larger scales, nodes could have positive effects at the population level by increasing the possibility of: (1) finding new habitats in a varying environment and (2) increased mate choice. In such cases nodes are not simply points that link pathways of movement, but are an attractive and valuable habitat.

Our results suggest that habitat nodes can affect the movement of individuals by increasing the ease of access to alternative habitats and routes along which they can move through the landscape, and induce, at least temporarily, a change in behaviour that results in them remaining in the vicinity. Graph and circuit theory have proved useful for evaluating connectivity in landscapes (Urban et al., 2009). Such analyses based on a randomwalk model show that additional pathways (e.g. nodes) slow the spread of organisms from point A to point B within a landscape (i.e. nodes create more movement options in between two arbitrary points resulting in some lateral population spreading instead of movement only in one direction; McRae et al., 2008). The slowing of spread could also be a function of the general attraction of nodes; thus, node attraction may have an important role in the dispersal and colonization of new areas by species (Berggren et al., 2001). In addition to facilitating movement through the landscape, nodes may be important for the breeding success of species living in fragmented landscapes and especially favourable for species that indulge in courtship-calling. Thus, in future landscape planning more consideration should be given to the connectivity between linear landscape elements as it is likely to be important in determining the movement and distribution of species.

ACKNOWLEDGEMENTS. We thank SLU for access to the land for the duration of the experiment. $\AA \mathrm{B} \& \mathrm{ML}$ were funded by the Swedish Research Council (FORMAS).

\section{REFERENCES}

BERGGREN A. 2004: Impact of grazing on individual male movement in Roesel's bush-cricket Metrioptera roeseli: One possible clue to species range expansion. - J. Insect Behav. 17: 419-429.

BERGGREN Å. 2005: The effect of conspecifics on individual male movement in Roesel's bush-cricket, Metrioptera roeseli. - Ecol. Entomol. 30: 480-483.

BERGGREN Å. 2009: Effects of population size, growth rate and landscape variables on immune responses in experimentally introduced bush-cricket populations. - Landsc. Ecol. 24: 749-757.

Berggren Å., Carlson A. \& Kindvall O. 2001: The effect of landscape composition on colonization success, growth rate and dispersal in introduced bush-crickets Metrioptera roeseli. - Ecology 70: 663-670.

Berggren Å., Birath B. \& Kindvall O. 2002: Effect of corridors and habitat edges on dispersal behavior, movement rates, and movement angles in Roesel's bush-cricket Metrioptera roeseli. - Cons. Biol. 16: 1562-1569.

Brouwers N.A., Newton A.C. \& Bailey S. 2011: The dispersal ability of wood cricket (Nemobius sylvestris) (Orthoptera: Gryllidae) in a wooded landscape. - Eur. J. Entomol. 108: $117-125$.

Brown G.P., Phillips B.L., Webb J.K. \& Shine R. 2006: Toad on the road: Use of roads as dispersal corridors by cane toads (Bufo marinus) at an invasion front in tropical Australia. Biol. Conserv. 133: 88-94.

Brudvig L.A., Damschen E.I., Tewksbury J.J., Haddad N.M. \& LeVEY D.J. 2009: Landscape connectivity promotes plant biodiversity spillover into non-target habitats. - Proc. Nat. Acad. Sci. 106: 9328-9332.

Burnham K.P.\& Anderson D.R. 2002: Model Selection and Multimodel Inference: a Practical Information-Theoretic Approach, 2nd ed. Springer, New York, 488 pp.

COOKE H.A. \& ZACK S. 2009: Use of standardized visual assessments of riparian and stream condition to manage riparian habitat in eastern Oregon. - Environ. Manag. 44: 173-184.

Davies Z.G. \& Pullin A.S. 2007: Are hedgerows effective corridors between fragments of woodland habitat? An evidencebased approach. - Landsc. Ecol. 22: 333-351.

De Jong J. \& Kindvall O. 1991: Cikadavårtbitaren Metrioptera roeseli - nykomling eller hotad relikt? [The Roesel's bushcricket Metrioptera roeseli - new in Sweden or a threatened relict species?] - Fauna Flora 86: 214-221.

Dramstad W.E., Olson J.K. \& Forman R.T.T. 1996: Landscape Ecology Principles in Landscape Architecture and Land-use Planning. Island Press, Washington, $80 \mathrm{pp}$.

Forman R.T.T. \& Gordon M. 1981: Patches and structural components for landscape ecology. - Bioscience 31: 733-740.

Garcia J.D.D., Arevalo J.R. \& Fernandez-Palacios J.M. 2007: Road edge effect on the abundance of the lizard (Gallotia gal- 
loti Sauria: Lacertidae) in two Canary Islands forests. - Biodivers. Conserv. 16: 2949-2963.

Gascoigne J., Berec L. \& Gregory S. 2009: Dangerously few liaisons: a review of mate-finding Allee effects. - Popul. Ecol. 51: 355-372.

GILliEs C.S. \& Clair C.C.S. 2008: Riparian corridors enhance movement of a forest specialist bird in fragmented tropical forest. - Proc. Nat. Acad. Sci. 105: 19774-19779.

GWYNNE D.T. 2001: Katydids and Bush-crickets: Reproductive Behaviour and Evolution of the Tettigoniidae. Cornell University Press, Ithaca, $317 \mathrm{pp}$.

INGRISCH S. 1986: The plurennial life cycles of the European Tettigoniidae (Insecta: Orthoptera), 1. The effect of temperature in embryonic development and hatching. - Oecologia 70: 606-616.

Jordan F., Magura T., Tóthmérész B., Vasas V. \& KösöBöcz V. 2007: Carabids (Coleoptera: Carabidae) in a forest patchwork: a connectivity analysis of the Bereg Plain landscape graph. - Landsc. Ecol. 22: 1527-1539.

Kindvall O., Vessby K., Berggren Å. \& Hartmann G. 1998: Individual mobility prevents an allee effect in sparse populations of the bush-cricket Metroptera roeseli: an experimental study. - Oikos 81: 449-457.

Lees A.C. \& Peres C.A. 2008: Conservation value of remnant riparian forest corridors of varying quality for Amazonian birds and mammals. - Conserv. Biol. 22: 439-449.

Marshall J.A. \& Haes E.C.M. 1988: Grasshoppers and Allied Insects of Great Britain and Ireland. Harley Books, Martins, Great Horkesley, Colchester, Essex, 252 pp.

Mcrae B.H., Dickson B.G., KeitT T.H. \& Shah V.B. 2008: Using circuit theory to model connectivity in ecology, evolution, and conservation. - Ecology 89: 2712-2724.

Pardini R., Marques de Souza S., Braga-Neto R. \& Metzger J.P. 2005: The role of forest structure, fragment size and cor- ridors in maintaining small mammal abundance and diversity in an Atlantic forest landscape. - Biol. Conserv. 124: 253-266.

Pettersson B. 1996: Nya fyndplatser för cikadavårtbitare Metrioptera roeseli norr om Mälaren. [New records of Roesel's bush-cricket, Metrioptera roeseli, north of Lake Mälaren.] Entomol. Tidskr. 117: 121-122.

Preuss S., Cassel-Lundhagen A. \& Berggren Å. 2011: Modelling the distribution of the invasive Roesel's bush-cricket (Metrioptera roeselii) in a fragmented landscape. - NeoBiota 11: 33-49.

Proulx S.R., Promislow D.E.L. \& Phillips P.C. 2005: Network thinking in ecology and evolution. - Trends Ecol. Evol. 20: 345-353.

Rasbash J., Steele F., Browne W.J. \& Goldstein H. 2009: A User's Guide to MLwiN. Centre for Multilevel Modelling. University of Bristol.

SöDERSTRÖm B. \& Hedblom M. 2007: Comparing movement of four butterfly species in experimental grassland strips. $-J$. Insect Conserv. 11: 333-342.

Tischendorf L. \& FAHRING L. 2000: On the usage and measurement of landscape connectivity. - Oikos 90: 7-19.

Urban D.L., Minor E.S, Treml E.A. \& Schick R.S. 2009: Graph models of habitat mosaics. - Ecol. Lett. 12: 260-273.

White G.C. \& Burnham K.P. 1999: Program MARK: survival estimation from populations of marked animals. - Bird Study 46: $120-138$.

Wood P.A. \& Samways M.J. 1991: Landscape element pattern and continuity of butterfly flight paths in an ecologically landscaped botanic garden, Natal, South Africa. - Biol. Conserv. 58: 149-166.

Received August 2, 2011; revised and accepted July 2, 2012 